\title{
Body mass index and duration of breast feeding: a survival analysis during the first six months of life
}

\author{
Ingrid H E Rutishauser, John B Carlin
}

\begin{abstract}
Study objective-The aim was to determine whether excess weight in lactating women is associated with earlier cessation of breastfeeding.
\end{abstract}

Design-The study was a prospective cohort analysis using a community sample of women.

Setting-Geelong the regional centre of the Barwon Region of Victoria, Australia, in 1984-85.

Subjects-All women who were breast feeding and whose first infant was born between 1 May 1984 and 30 April 1985 were asked to participate. Of these, 739 women participated, a response rate of $81 \%$.

Main results-Smoking, mother's age and occupation, the time the infant was first put to the breast, and mother's body mass index at one month postpartum all exerted statistically significant independent effects on the duration of breast feeding, assessed using Cox's proportional hazards regression modelling. The strongest effects were for smoking, with an adjusted relative risk for cessation of breast feeding of $2 \cdot 5(95 \% \mathrm{CI}$ 1.9 to $3 \cdot 1$ ) for 10 cigarettes per day $v$ no smoking, and maternal age, with relative risk of $2 \cdot 2(95 \%$ CI $1 \cdot 5$ to $3 \cdot 1)$ for a 20 year old mother relative to a 30 year old. The relative risk for women with a body mass index above 26 was $1.5(95 \%$ CI 1.1 to $2 \cdot 0)$.

Conclusions-Excess weight at one month postpartum, as determined by a body mass index above the normal range, was found to be an independent risk factor for early cessation of breast feeding and together with smoking, maternal age, occupation, and the time the infant is first put to the breast can be used to identify, early in the postpartum period, those women most likely to benefit from counselling in order to breast feed their infants successfully.

f Epidemiol Community Health 1992; 46: 559-565

Department of

Human Nutrition,

Geelong, Victoria

3217, Australia

I H E Rutishauser

Clinical Epidemiology

and Biostatistics Unit

Royal Children's

Hospital, Parkville,

Hospital, Parkville,

J B Carlin

Correspondence to:

I H E Rutishauser

Accepted for publication March 1992 may be marginally undernourished by generally accepted standards.

Many factors influence the pattern and duration of breast feeding. In general, older, better educated women who are relatively well off socioeconomically, who live in a stable relationship, and who have support for breast feeding from friends, relatives, and husbands continue to breast feed longer. ${ }^{13-18} \mathrm{An}$ important way in which these characteristics influence the duration of breast feeding appears to be by reducing the concerns that mothers have about the demands of breast feeding on themselves, their families, and their ability to return to work. ${ }^{19}$ Feeding schedule, in particular an increased frequency of feeding, is also associated with a longer duration of breast feeding, ${ }^{20}$ while the use of combined oral contraceptives and smoking are both associated with a shorter duration of breast feeding. ${ }^{17}$ 21-23

Studies of the influence of diet and nutritional status on lactational performance have focused primarily on milk volume and composition ${ }^{24-27}$ and have generally shown only small differences between women from affluent and developing countries despite large differences in reported energy intakes and nutritional status. ${ }^{28} 29$ Duration of breast feeding in relation to maternal nutritional status does not appear to have been specifically studied in well nourished women in industrialised countries. It has, however, been reported that successful breast feeding in this context is associated with an increase in appetite, an increased energy intake, and a lower rate of maternal weight loss while breast feeding, ${ }^{30-32}$ and also that mothers advised to increase their energy intake while breast feeding weaned their infants significantly later than mothers who did not receive such advice. ${ }^{33}$

The hypothesis tested in this study, namely that a body mass index above the normal range in lactating women is associated with earlier cessation of breast feeding and an increased prevalence of "insufficient milk syndrome", arose from a small prospective study, carried out in 1981 in Geelong, a regional centre of 150000 people $80 \mathrm{~km}$ southwest of Melbourne, Victoria, to find out more about factors related to the duration of breast feeding in this population. ${ }^{34}$ In addition to the demographic and behavioural characteristics commonly asssociated with early cessation of breast feeding, this study found a number of nutrition related characteristics to be associated with the duration of breast feeding. In particular, women who stopped breast feeding by three months, on average, had a higher body mass index but a lower intake of energy and less frequently experienced an increase in appetite with lactation than those who breast fed for longer. Taken 
together these findings suggested the possibility that excess energy reserves might be a factor limiting lactation in this group of women. If confirmed, an association between a body mass index above the normal range and earlier cessation of breast feeding would be of relevance to infant welfare nurses and others responsible for providing advice and support to breast feeding women as a means of identifying, at an early stage, individuals who might benefit from appropriate counselling and advice in order to continue breast feeding their infants successfully.

\section{Methods}

STUDY POPULATION

On the basis of information on the distribution of body mass index in Australian women ${ }^{35}$ it was estimated that a sample of at least 300 breast feeding women was required to detect a relative risk of 1.5 for earlier cessation of breast feeding, with $80 \%$ power and a significance level of $5 \%$, in women with a body mass index above 25 compared with those with one in the normal range $(20-25)$. In order to obtain a group of this size, all women whose first infant was born between May 11984 and April 30 1985, who chose to breast feed and who were attending an infant welfare centre in the Barwon region of Victoria were invited to participate in the study. The study was deliberately confined to primiparous women in order to increase the homogeneity of the group with respect to influences on the duration of breast feeding that would be difficult to quantify or control for, such as previous experience with breast feeding and family related commitments.

\section{STUDY MEASUREMENTS}

At their first visit to the infant welfare centre after the birth of their baby all women eligible for the study, that is, those who were still breast feeding their firstborn infant, were informed about the study by the infant welfare nurse and invited to participate. If they agreed to do so a study record card was completed by the nurse and filed with their infant welfare centre record. These records routinely provide information on the infant's gender, birthweight, and date of birth, on the occupation of both parents, and on the mother's age.

Information obtained specifically for the study included the mother's weight and height, smoking, appetite, oral contraceptive use, and details about the time of initiation of breast feeding and early formula feeding. The mother's weight, in light indoor clothing and shoes, was recorded to the nearest $\mathrm{kg}$ and height, without shoes, to the nearest $0.5 \mathrm{~cm}$. All mothers were also asked to report their prepregnancy body weight, if known.

At the first infant welfare clinic visit information was obtained from each mother about curren smoking habits, changes in appetite since the start of breast feeding, and any problems experienced with breast feeding. At all subsequent visits up to six months postpartum, or until the date of cessation of breast feeding, whichever occurred first, the infant welfare nurse recorded any changes in relation to the above information and also asked about oral contraceptive use and the mother's employment status.
The date of cessation of breast feeding was chosen as the outcome measure in the present study because it is readily identified and avoided any possible problems with the definition of "sole breast feeding". Each mother was also asked to give her reason for stopping breast feeding.

\section{DATA HANDLING AND STATISTICAL ANALYSIS}

The infant welfare nurses were responsible for all data collection procedures throughout the study. After all relevant records had been received the data were coded for computer entry and checked (by IR) against the original record. All dates were coded as a five digit decimal date ${ }^{36}$ and parents' occupation was coded using the Daniel occupational prestige score. ${ }^{37}$ Occupations not listed by Daniel were assigned a Daniel score by reference to information provided in the Australian standard classification of occupations. ${ }^{38}$ Body mass index was calculated from weight and height as $\mathrm{kg} / \mathrm{m}^{2}$ and a value of 26 rather than the usual value of 25 was taken as the upper limit of the normal range, in order to allow for the extra adipose tissue gained during pregnancy.

Exploratory data analysis was carried out using the Minitab statistical package. ${ }^{39}$ However, in order to utilise fully the observations on subjects who were still breast feeding at six months postpartum and others for whom follow up data were incomplete, survival analysis was used to explore the effects of different variables on the time course of breast feeding. The effects of individual variables on the "survival" of breast feeding were initially assessed using the KaplanMeier product limit estimate of survival. ${ }^{40}$ This estimate avoids an arbitrary choice of time interval for estimating the percentage of surviviors. The equality of survival curves, based on subgroups defined by a given variable, was tested using the Mantel-Cox statistic given by the program BMDP1L. ${ }^{40}$

Variables found to have a significant effect on the survival of breast feeding were investigated using Cox's proportional hazards model, ${ }^{41} 42$ which allows joint estimation of the effects of independent variables on the hazard or risk of cessation of breast feeding. The coefficients of these covariates were estimated using the program BMDP2L and the effects of the regressor variables in the proportional hazards model were tested using the likelihood ratio statistic. ${ }^{40}$ Major comparisons are displayed graphically using adjusted survival curves which are obtained by stratifying on the variable of interest while fixing other covariates at convenient values. ${ }^{42}$

\section{Results}

CHARACTERISTICS OF THE STUDY POPULATION

A total of 870 records for firstborn breast fed infants was obtained. This amounts to a response rate of $87 \%$ based on an estimated proportion of $41 \%$ of births to mothers with no previous issue; an $85 \%$ prevalence of breast feeding on discharge from hospital; and an infant welfare centre contact rate of $95 \%{ }^{64344}$ Only 739 of these records were suitable for analysis of the association between body mass index and the duration of breast feeding. Seventy three mothers had stopped breast feeding within the first $14 \mathrm{~d}$ postpartum. 
These mothers were considered not to have established lactation and consequently not to be appropriate subjects for the study. Twenty three mothers either did not attend the infant welfare centre or did not wish to participate after their first visit, and for 35 others information essential for the study was inadvertently omitted from the records. Table I shows summary statistics for the 739 women who breast fed their infants for at least $14 \mathrm{~d}$. Missing data for one or more variables (see table I) reduced the number of records available for multivariate analysis to between 570 and 600 , depending on the variables included in the model. The mean prepregnancy weight and height of the study population were similar to those in a national sample of Australian women of the same age measured in 1983 by the National Heart Foundation of Australia, ${ }^{45}$ and the median birthweight of the infants approximated the 50th centile value of the internationally accepted reference standards for growth, ${ }^{46}$ adopted for use in Australia.

UNIVARIATE ANALYSIS OF FACTORS INFLUENCING THE DURATION OF BREAST FEEDING

Table II gives the Mantel-Cox statistic, degrees of freedom, and $p$ values for the equality of breast

Table I Summary statistics for 739 women who breast fed their infants for at least $14 d$

\begin{tabular}{|c|c|c|c|c|c|c|}
\hline Variable & Mean & Median & $S D$ & Min & $\operatorname{Max}$ & $n$ \\
\hline $\begin{array}{l}\text { Age (years) } \\
\text { Mother's occupation (score) } \\
\text { Father's occupation (score) } \\
\text { Prepregnancy weight (kg) } \\
\text { Height (cm) } \\
\text { Postpartum weight (kg) }\end{array}$ & $\begin{array}{r}25 \cdot 3 \\
4 \cdot 8 \\
4 \cdot 7 \\
58 \cdot 3 \\
163 \cdot 4\end{array}$ & $\begin{array}{c}25 \\
4.9 \\
4 \cdot 7 \\
57 \\
163\end{array}$ & $\begin{array}{l}4 \cdot 0 \\
0.91 \\
1.08 \\
8 \cdot 8 \\
6 \cdot 4\end{array}$ & $\begin{array}{c}15 \\
2.4 \\
1.4 \\
38 \\
145\end{array}$ & $\begin{array}{c}41 \\
6 \cdot 7 \\
6 \cdot 7 \\
103 \\
186\end{array}$ & $\begin{array}{l}717 \\
648 \\
685 \\
715 \\
703\end{array}$ \\
\hline $\begin{array}{l}\text { first visit } \\
1 \text { month } \\
3 \text { months } \\
6 \text { months } \\
\text { Infant birth weight (g) } \\
\text { Time first fed (hours after birth) } \\
\text { Cigarettes smoked (No at first visit) } \\
\text { BMI at } 1 \text { month (kg/m) }\end{array}$ & $\begin{array}{r}63 \cdot 3 \\
62 \cdot 6 \\
61 \cdot 1 \\
59 \cdot 9 \\
3307 \\
6 \cdot 4 \\
2 \cdot 8 \\
23 \cdot 5\end{array}$ & $\begin{array}{c}62 \\
61 \\
60 \\
59 \\
3340 \\
1 \cdot 0 \\
0 \\
23 \cdot 0\end{array}$ & $\begin{array}{r}9 \cdot 7 \\
9 \cdot 5 \\
9 \cdot 3 \\
9 \cdot 7 \\
514 \\
14 \cdot 2 \\
6 \cdot 0 \\
3 \cdot 3\end{array}$ & $\begin{array}{c}41 \\
40 \\
42 \\
42 \\
1260 \\
0 \\
0 \\
15 \cdot 2\end{array}$ & $\begin{array}{l}114 \\
110 \\
103 \\
111 \\
5100 \\
99 \\
50 \\
38 \cdot 5\end{array}$ & $\begin{array}{l}725 \\
712 \\
663 \\
618 \\
715 \\
718 \\
720 \\
681\end{array}$ \\
\hline
\end{tabular}

Table II Mantel-Cox statistic for the equality of breast feeding survival curves for variables tested for their effect on the duration of breast feeding

\begin{tabular}{|c|c|c|c|c|}
\hline \multicolumn{2}{|c|}{ Variable $^{a}$} & \multicolumn{2}{|c|}{$\begin{array}{l}\text { Mantel-Cox } \\
\text { statistic df }\end{array}$} & $p$ \\
\hline $\begin{array}{l}\text { Infant: } \\
\text { Father: } \\
\text { Mother: }\end{array}$ & $\begin{array}{l}\text { Gender } \\
\text { Birthweight the first visit postpartum } \\
\text { Time first breast fed } \\
\text { Occupation score } \\
\text { Occupation score } \\
\text { Age } \\
\text { Height } \\
\text { Prepregnancy weight } \\
\text { Number of cigarettes smoked } \\
\text { Change in appetite with breast feeding }\end{array}$ & $\begin{array}{r}0 \cdot 1 \\
1 \cdot 0 \\
14 \cdot 7 \\
29 \cdot 0 \\
33 \cdot 3 \\
77 \cdot 6 \\
2 \cdot 9 \\
6 \cdot 1 \\
96 \cdot 9 \\
10 \cdot 1\end{array}$ & $\begin{array}{l}1 \\
3 \\
3 \\
3 \\
3 \\
3 \\
4 \\
3 \\
2 \\
2\end{array}$ & $\begin{array}{l}0 \cdot 7927 \\
0 \cdot 8076 \\
0 \cdot 0021 \\
0 \cdot 0000 \\
0 \cdot 0000 \\
0 \cdot 0000 \\
0 \cdot 5695 \\
0 \cdot 1049 \\
0 \cdot 0000 \\
0 \cdot 0064\end{array}$ \\
\hline & $\begin{array}{l}\text { Body mass index } 1 \text { month postpartum } \\
\text { Weight gain relative to prepregnancy weight }\end{array}$ & $\begin{array}{r}14 \cdot 3 \\
5 \cdot 9\end{array}$ & $\begin{array}{l}3 \\
2\end{array}$ & $\begin{array}{l}0.0025 \\
0.0520\end{array}$ \\
\hline & $\begin{array}{l}\text { Wt } 6 \text { months postpartum } \\
\text { Weight loss since } 1 \text { month postpartum } \\
\text { Weight relative to prepregnancy weight } \\
\text { Oral contraceptive use while breast feeding }\end{array}$ & $\begin{array}{r}13 \cdot 2 \\
25 \cdot 0 \\
1 \cdot 1\end{array}$ & $\begin{array}{l}2 \\
3 \\
1\end{array}$ & $\begin{array}{l}0.0013 \\
0.0000 \\
0.2904\end{array}$ \\
\hline
\end{tabular}

df= degrees of freedom

Birthweight: <2500, 2501-3000, 3001-3500, and >3500

Time first breast fed: $<1,1-6,7-12$, and $>12$ h

Occupation score: $<3 \cdot 0,3 \cdot 1-4 \cdot 5,4 \cdot 6-5 \cdot 5$, and $>5 \cdot 5$

Age: $<20,21-25,26-30$, and $>30$ years

Height: $<155,156-160,161-165,166-170$, and $>170 \mathrm{~cm}$

Prepregnancy weight: $<50,51-55,56-65$, and $>65 \mathrm{~kg}$

Number of cigarettes smoked daily: $0,1-10$, and $>10$

Change in appetite with breast feeding: decrease, no change, and increase

Weight gain relative to prepregnancy weight at 1 month postpartum

$-<1,1-5$, and $>5 \mathrm{~kg}$; and at 6 months postpartum: loss, $<1,1-5$, and $>5 \mathrm{~kg}$

Weight loss since 1 month post partum: $<1,1-5$, and $>5 k$

Oral contraceptives while breast feeding: used and not used. feeding survival curves for the variables tested individually for their effect on the duration of breast feeding. Maternal smoking and age, and the parents' occupation score, had the greatest association with the duration of breast feeding in the first six months postpartum. Other variables with a lesser but statistically significant effect $(p<0.05)$ included the time after birth at which the infant was first put to the breast, the mother's body mass index at one month postpartum, and changes in maternal appetite with breast feeding. Variables without any significant influence on the duration of breast feeding included the infant's sex and birthweight, the mother's prepregnancy weight and height, the amount of pregnancy weight gain retained at one month postpartum, and oral contraceptive use while breast feeding. At six months postpartum the amount of maternal weight change, both relative to prepregnancy weight and to weight at one month postpartum, was associated with significant differences in breast feeding survival curves.

MULTIVARIATE ANALYSIS OF FACTORS INFLUENCING THE DURATION OF BREAST FEEDING

In order to assess the effects of body mass index on the duration of breast feeding while allowing for the effects of the other variables that had a significant influence on the duration of breast feeding when considered individually, the data were analysed using the Cox proportional hazards model. Variables were included in the model only if they were not highly correlated with other variables in the model and if they could be used as predictors of the duration of breast feeding, in the sense of values observed before or soon after the time of birth (leading, for example, to the omission of weight change variables observed at six months postpartum). Table III shows the regression coefficients and significance levels obtained from the program BMDP2L for the variables included. Of these only four (smoking, mother's age, the time after birth when the infant was first put to the breast, and mother's body mass index at one month postpartum) exerted significant independent effects in the model as determined by the ratio of their coefficients relative to their standard errors. The values for the likelihood ratio statistic for the six most significant effects are also given in table III and the $p$ values suggest qualitatively similar conclusions to the coefficient estimates. Tests to confirm that these variables met the assumptions of the proportional hazards model led to some changes in the definition of the variables entered to satisfy better the proportionality and linearity criteria of the model (see table IV), but this had no effect on any of our substantive conclusions. However, representing socioeconomic status as mother's occupation score produced a slightly stronger effect than when father's score was used. More importantly it appeared that the effect of body mass index was due to a difference between women in the normal range $(<26)$ and those above the normal range, while no evidence for a dose-response relationship was found within the normal range.

No statistically significant interaction effects were found between the variables in the model. However, since the effect of smoking on the rate of 
cessation of breast feeding was much greater than that of any of the other variables included in the model, the consistency of the other parameter estimates was tested in the non-smokers alone. Table IV indicates that the regression coefficients and their significance were largely unaffected by the exclusion of smokers from the model. More specifically the effect of age remained essentially unchanged while that of mother's occupation score decreased. The effect both of the time the infant was first put to the breast and of body mass index on the rate of cessation of breast feeding, however, appeared to be somewhat more pronounced in the non-smokers. It could therefore be concluded that body mass index exerted a significant effect on the rate of cessation of breast feeding in non-smokers as well as in the study populations as a whole.

INTERPRETATION OF THE ESTIMATES FROM THE PROPORTIONAL HAZARDS MODEL

In practical terms the ratio of hazards can be regarded as the relative risk of the variable in question for the rate of cessation of breast feeding. Table $\mathrm{V}$ gives estimates for the relative risk together with $95 \%$ confidence intervals calculated for specified values of the five variables included in the final model. As already seen, smoking and

Table III Regression coefficients and significance levels obtained from the program $B M D P 2 L$ for variables included in the Cox proportional hazards model $(n=570)$.

\begin{tabular}{|c|c|c|c|}
\hline Variable $^{a}$ & $\begin{array}{l}\text { Regression } \\
\text { coefficient }\end{array}$ & $S E$ & $\frac{\text { Coefficient }}{S E}$ \\
\hline \multirow[t]{3}{*}{$\begin{array}{l}\text { Smoking } \\
\text { Age } \\
\text { Time first breast fed } \\
\text { BMI } \\
\text { Occupation score } \\
\text { Occupation score } 1 \\
\text { Oral contraceptives } \\
\text { Appetite change } \\
\text { Pregnancy weight gain } \\
\text { Infant's gender }\end{array}$} & $\begin{array}{r}0.8018 \\
-0.0981 \\
0.3645 \\
0.0533 \\
-0 \cdot 5014 \\
-0 \cdot 1444 \\
-0 \cdot 2130 \\
0 \cdot 1338 \\
-0.0128 \\
-0.0525\end{array}$ & $\begin{array}{l}0 \cdot 1376 \\
0.0193 \\
0 \cdot 1380 \\
0.0205 \\
0 \cdot 3029 \\
0 \cdot 1407 \\
0 \cdot 1293 \\
0 \cdot 1435 \\
0.0147 \\
0 \cdot 1270\end{array}$ & $\begin{array}{r}5 \cdot 8252 \\
-5.0769 \\
2.6420 \\
2.5962 \\
-1.6552 \\
-1.0264 \\
-1.6468 \\
0.9327 \\
-0.8682 \\
-0.4137\end{array}$ \\
\hline & Likelil & Dato & effects tested \\
\hline & $\chi^{2}$ & $d f$ & p value \\
\hline $\begin{array}{l}\text { Smoking } \\
\text { Age } \\
\text { BMI } \\
\text { Time first breast fed } \\
\text { Occupation score } 2 \\
\text { Oral contraceptives }\end{array}$ & $\begin{array}{r}31 \cdot 46 \\
26 \cdot 70 \\
6 \cdot 46 \\
6 \cdot 77 \\
3 \cdot 07 \\
2 \cdot 71\end{array}$ & $\begin{array}{l}1 \\
1 \\
1 \\
1 \\
2 \\
1\end{array}$ & $\begin{array}{l}0 \cdot 0000 \\
0 \cdot 0000 \\
0 \cdot 0110 \\
0 \cdot 0093 \\
0 \cdot 0798 \\
0 \cdot 0995\end{array}$ \\
\hline
\end{tabular}

$\mathrm{BMI}=$ body mass index

${ }^{a}$ Definition of variables:

Smoking coded 1 for smokers and 0 otherwise Age in years

Time first breast fed in hours expressed as logarithm to the base 10

Body mass index in $\mathrm{kg} /$ metre of height squared

Occupation score entered as a categorical variable with three levels and two degrees of freedom defined as follows: score 1 coded as 1 for values between 3 and 5 and 0 otherwise, and score 2 coded as 1 for scores $<3$ and 0 otherwise

Oral contraceptives coded 1 for users and 0 otherwise Appetite change coded as 1 for an increase and 0 otherwise Pretite change coded as 1 for an increase and Infant's gender coded as 1 for males and 2 for females

Table IV Comparison of the parameters of the proportional hazards model for all available data and for data from non-smokers only

\begin{tabular}{|c|c|c|c|c|}
\hline \multirow[b]{2}{*}{ Variable $^{a}$} & \multicolumn{2}{|c|}{$\begin{array}{l}\text { All cases with complete data } \\
(n=579)\end{array}$} & \multicolumn{2}{|c|}{$\begin{array}{l}\text { Non-smokers only } \\
(n=434)\end{array}$} \\
\hline & $\begin{array}{l}\text { Regression } \\
\text { coefficient }\end{array}$ & $\frac{\text { Coefficient }}{S E}$ & $\begin{array}{l}\text { Regression } \\
\text { coefficient }\end{array}$ & $\frac{\text { Coefficient }}{S E}$ \\
\hline $\begin{array}{l}\text { Age } \\
\text { Smoking }\end{array}$ & $\begin{array}{r}-0.0787 \\
0.9065\end{array}$ & $\begin{array}{r}-4 \cdot 38 \\
7 \cdot 12\end{array}$ & $\begin{array}{r}-0 \cdot 1048 \\
-\end{array}$ & $\begin{array}{r}-4 \cdot 24 \\
-\end{array}$ \\
\hline Occupation score & 0.4728 & 3.07 & $0 \cdot 3685$ & 1.96 \\
\hline Time first breast fed & $0 \cdot 2942$ & $2 \cdot 24$ & 0.5142 & $3 \cdot 16$ \\
\hline Body mass index & 0.4068 & $2 \cdot 68$ & 0.5379 & $2 \cdot 91$ \\
\hline
\end{tabular}

maternal age had the greatest effect on the hazard for cessation of breast feeding. The estimated effect of smoking when represented as a relative risk indicates that a 10 cigarettes per day smoker was about 2.5 times more likely to stop breast feeding at any time than a non-smoker. In contrast maternal age had a negative effect on the hazard so that a woman aged 30 years was only about half as likely to stop breast feeding at any time as a woman aged 20 years after controlling for the other variables in the model. Mother's occupation score, body mass index, and the time the infant was first put to the breast after birth each produced an increase in the hazard of around $50 \%$ for comparison categories specified in table $\mathrm{V}$.

Table $V$ Estimates of the relative risk (hazard ratio) for relevant values of the covariates included in the proportional hazards model

\begin{tabular}{ll}
\hline Covariate & $\begin{array}{l}\text { Relative risk } \\
\left(95^{\circ}{ }_{0} C I\right)\end{array}$ \\
\hline Smoking (10 cigarettes/non-smoker) & $\begin{array}{l}2.48 \\
(1.92\end{array}$ \\
Maternal age (30 years/20 years) & 0.45 \\
& $(0.32$ to $0 \cdot 65)$ \\
Mother's occupation score $(>4 /<4)$ & 1.60 \\
& $(1 \cdot 18$ to $2 \cdot 18)$ \\
Body mass index $(>26 /<26)$ & 1.50 \\
Time first breast fed $(12 \mathrm{~h} /<1 \mathrm{~h})$ & $(1.11$ to $2 \cdot 04)$ \\
& $(1.03$ to $1 \cdot 82)$ \\
\hline
\end{tabular}

$\overline{C I}=$ confidence interval

Figures 1-3 illustrate graphically the principal findings from the study in terms of adjusted survival curves based on the proportional hazards model and stratified respectively by smoking (fig 1), maternal age (fig 2), and body mass index (fig 3 ). On the basis of these curves the estimated proportion of non-smokers still breast feeding at six months of age was $50 \%$ compared with $20 \%$ in smokers; $80 \%$ in women aged $>30$ years compared with $30 \%$ in women aged 20 years or less, and $50 \%$ in women with a body mass index within the normal range as compared with $40 \%$ in women with a body mass index above the normal range.

\section{Discussion}

The primary aim of the present study was to determine if a higher body mass index is associated with a reduced duration of breast feeding, as suggested by the pilot study of McKay. ${ }^{34}$ Although a considerable amount of work has been done on factors related to the duration of breast feeding in western societies the possibility that over- rather than undernutrition has a negative association with the duration of breast feeding has not previously been studied.

The majority of studies that have reported on factors influencing the duration of breast feeding have studied women attending a particular maternity or paediatric primary care facility and the population is therefore not necessarily representative of the wider population of breast feeding women. $25910152347-49$ In addition, maternity unit based populations require special arrangements to be made for subsequent follow up. Studies that are more likely to provide data representative of the population at large are those based on regional or national birth cohorts. Because in such studies subjects are often distri- 
buted over a wide geographical area these studies generally involve using mailed questionnaires and are therefore subject to the limitations inherent in this approach, such as non-return of questionnaires and incomplete or inaccurate responses to questions. $^{3650}$ Studies involving a city or a small regional cohort such as the present study afford both the possibility of a representative study group and direct and ongoing contact with participants. $^{25910152347-49}$

Direct comparison with data from other studies is difficult not only because of demographic and other differences between study populations but also because the number and kind of variables included differ from study to study. In addition many studies have simply reported univariate effects and only some have adjusted for the effects

Figure 1 Duration of breast feeding by smoking status. Survival curves are adjusted via Cox proportional hazards regression modelling to representative values of the following covariates (values in parentheses): (values in parentheses): body mass index $(<26)$, time first breast fed (within first hour), and mother's socioeconomic status (lower of two categories).

Figure 2 Duration of breaset feeding by maternal age category. Survival curves are adjusted via Cox proportion hazards regression modelling to

representative values of the following covariates (values in parentheses): mother's smoking status (non-smoker), body mass index $(<26)$, time first breast fed (within first hour), and mother's socioeconomic status (lower of two categories).

Figure 3 Duration of breast feeding by body mass index (BMI) category. Survival curves are adjusted via Cox proportional hazards regression modelling to representative values of representative values of
the following covariates (values in parentheses): age of mother ( 25 years), smoking status (nonsmoker), time first breast fed (within first hour), and mother's

socioeconomic status

(lower of two categories).
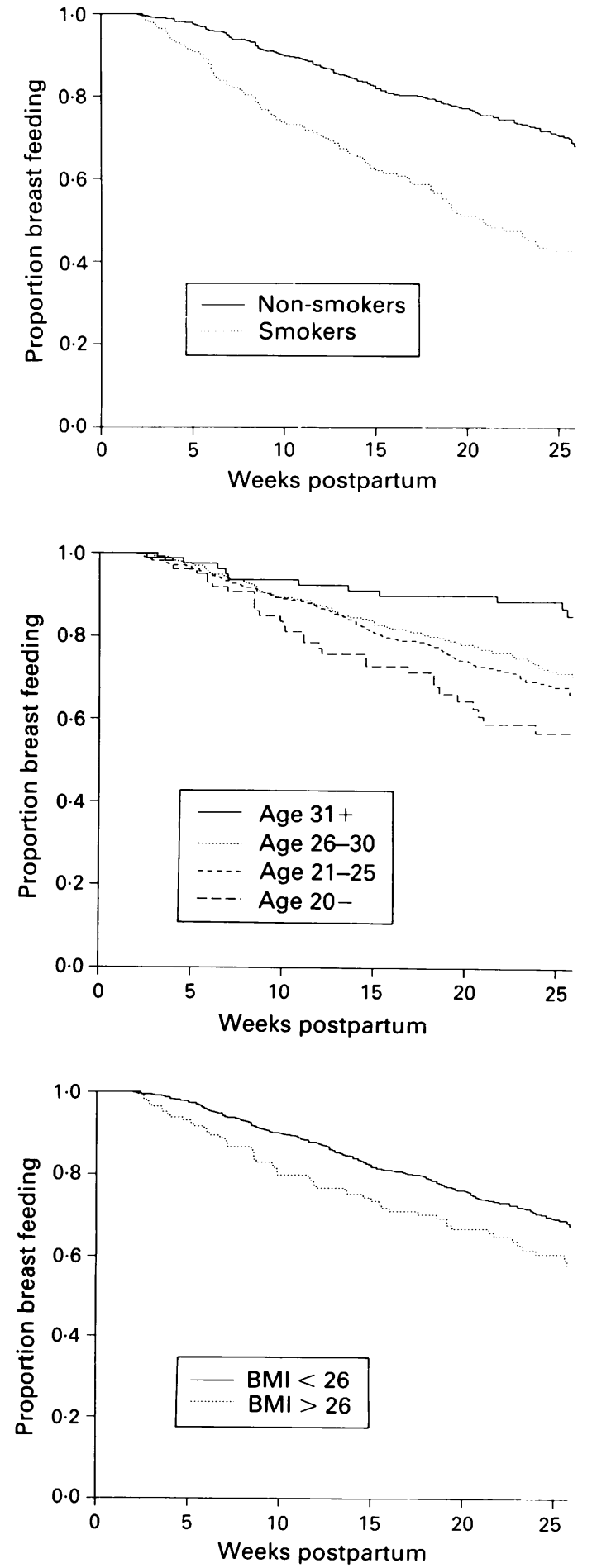

of covariates by means of partial correlation coefficients or other multivariate methods of analysis. ${ }^{15} 16485152$ Kurinij et al, ${ }^{16}$ who used the Cox proportional hazards model to adjust for covariates, found that in white women maternal age, education, and being married were all associated with an increased duration of breast feeding while formula supplements in hospital had a negative effect. Maternal age, education, and the support of a partner were also found to be significantly associated with the success of breast feeding in the study of Starling et al, ${ }^{51}$ while Samuels et al, ${ }^{15}$ who used discriminant analysis to test the influence of variables on the duration of breast feeding, found that after race maternal age and receiving formula in hospital had the most significant impact.

None of the studies so far discussed included information on the effects of smoking or the timing of the first breast feed on the duration of breast feeding. Several other studies have, however, reported findings for smoking similar to those of the present study. ${ }^{22} 2350$ In all these studies the negative effect of smoking on the duration of breast feeding was independent of the effect of social class but none of these studies controlled for the effects of other independent influences such as age. In the largest of these studies, ${ }^{50} 36^{\circ}{ }_{\text {o }}$ of non-smokers were still breast feeding at six months compared with $19^{\circ}{ }_{0}$ of smokers. These figures are broadly similar to the respective adjusted survival estimates of $50^{\circ}{ }_{0}$ and $20^{\circ}{ }_{o}$ for non-smokers and smokers in the present study.

A significant effect of early contact and suckling by the infant on the duration of breast feeding was first reported by de Chateau et $a l^{53}$ and later by Salariya et $a l^{20}$ and Wright and Walker. ${ }^{14}$ in Salariya's study the association was independent of age and social class since the study groups were matched on these variables, but in the study of Wright and Walker the observed association may have been indirect since the timing of the first feed was also significantly associated with maternal education and social class. In the present study the independent effect of early feeding was less significant $(p<0.05)$ than the effect of maternal smoking or age $(p<0.001)$ or of occupation score and body mass index $(p<0.01)$. Although information on early formula supplementation was not included in the present study it was to some extent controlled for by the exclusion of women who stopped breast feeding within the first two weeks postpartum since this appears to be the period when its influence on the cessation of breast feeding is most marked. ${ }^{4} 15$

The finding from a previous small study of 55 primparous women ${ }^{34}$ that those with a higher body mass index stopped breast feeding earlier was confirmed by the present study, in which it was found that after adjusting for the effects of smoking, age, mother's occupation, and time of the first breast feed, body mass index had a significant independent effect on the rate of cessation of breast feeding $(p<0.01)$. Compared with women in the normal range for body mass index the rate of cessation of breast feeding in women with an index above the normal range ( $>26$ ) was about $50^{\circ}{ }_{0}$, higher during the first six months postpartum. Within the normal range of 
body mass index no dose-response relationship was observed. Only 30 women had an index above 30 , the value normally considered as the cut off level for obesity. Of these 30 women, $11(37 \%)$ breast fed for less than 60 days compared with $18 \%$ of those whose index lay between 26 and 30 and $12 \%$ of those with an index in the normal range $\left(\chi^{2}=15.6, \mathrm{df}=2, \mathrm{p}<0.001\right)$. This suggests that above the normal range there was a doseresponse relationship between body mass index and early cessation of breast feeding.

Although identifying the mechanism for the relationship between body mass index and early cessation of breast feeding was not the purpose of the present study it was hoped that the study would provide some indication as to whether the mechanism was likely to have a physiological or a sociocultural basis. Women with a body mass index greater than 26 clearly do not have reduced or inadequate energy stores for lactation, but it is possible that such women may attempt to diet while breast feeding in order to increase weight loss. Depending on the extent of reduction in energy intake it is possible that dieting could compromise the ability to breast feed successfully. ${ }^{27}{ }^{54}$ In the absence of information on dietary intake the amount of postpartum weight loss was used to provide an indication of energy balance and therefore of the likelihood of "dieting". The present study found no evidence for a greater rate of postpartum weight loss by women with a body mass index $>26$; in fact the reverse trend was found when weight loss was stratified by the duration of breast feeding and compared for the two body mass index groups. Dugdale and EatonEvans, in another study of Australian women, have also observed that women with a high body mass index at one month postpartum had a tendency to have lost less weight by six months postpartum. ${ }^{55}$ Studies of hormonal profiles (prolactin and insulin) in women with varying amounts of weight gain at one month postpartum may be able to clarify the basis for the lower postpartum rate of weight loss in women with a body mass index above the normal range.

Since "inadequate lactation" or "a poor milk supply" are commonly given as reasons for early cessation of breast feeding by women in western societies the present study also explored the possibility that this explanation for early cessation of breast feeding is positively related to body mass index. The data obtained did not support the relationship and women with a body mass index above the normal range were in fact found to give inadequate lactation as a reason for early cessation of breast feeding significantly less often $(p<0.05)$ than those whose index lay in the normal range. It is thus possible that a concern about lack of weight loss while breast feeding may be the basis for the link between body mass index and the duration of breast feeding found in this study, although this was not a reason volunteered by the mothers themselves.

The study would not have been possible without the support of the Health Department of Victoria, Donna Mant-Smith, the Infant Welfare Nurses of the Barwon Region, and the mothers who participated. Our thanks go also to Dr Prasong Tienboon and Ms Elizabeth Thorne for technical assistance.
1 Smibert J, The return to breastfeeding (letter). Med $\mathcal{f}$ Aust 1978; 2: 533.

2 Coles EC, Cotter S, Valman HB. Increasing prevalence of breastfeeding. $B M F$ 1979; ii: 1122.

3 Martinez GA, Nalezienski JP. 1980 update: the recent trend in breastfeeding. Pediatrics 1981; 67: 260-3.

4 Martin J, Monk J, eds. Infant feeding 1980. Social Survey Division, Office of Population Censuses and Surveys. London: OPCS, 1982.

5 Gunn TR. The incidence of breastfeeding and reasons for weaning. NZ Med $\mathcal{1}$ 1984; 97: 360-3.

6 Palmer N. Breastfeeding- the Australian situation 7 Food Nutr 1985; 42: 13-18.

7 Cole JP. Breastfeeding in the Boston suburbs in relation to personal-social factors. Clin Pediatr (Phila) 1977; 16 352-6.

8 Sjolin S, Hofander Y, Hillervik C. Factors related to early termination of breastfeeding. Acta Paediatr Scand 1977, 66: 505-11.

9 Borda EC, Feeny EM, Morris MM, Gupta JM. Current patterns of breastfeeding in a New South Wales Maternity Hospital. Med ₹ Aust 1978; 2: 250-3.

10 West CP. Factors influencing the duration of breastfeeding. f Biosoc Sci 1980; 12: 325-31.

11 Gussler JD, Briesemeister LH. The insufficient milk syndrome: a biocultural explanation. Med Anthropol 1980 4: 3-24.

12 World Health Organization. Contemporary patterns of breast feeding. Report on the WHO Collaborative Study on Breastfeeding. Geneva: WHO, 1981.

13 Martin J, White A, eds. Infant feeding 1980. Office of Population Censuses and Surveys (OPCS), Social Survey Division. London: HMSO, 1988.

14 Wright HJ, Walker PC. Predicition of duration of breastfeeding in primiparas. $\mathcal{F}$ Epidemiol Community Health 1983; 37: 89-94.

15 Samuels SE, Margen S, Schoen EJ. Incidence and duration of breastfeeding in a health maintenance organisation population. Am ₹ Clin Nutr 1985; 42: 504-10.

16 Kurinij N, Shiono PH. Rhoads GG. Breastfeeding incidence and duration in black and white women. Pediatrics $1988 ; 81$ : 365-71.

17 Lyon AJ. Factors infuencing breastfeeding. Acta Paediatr Scand 1984; 73: 268-70.

18 Sjolin S, Hofander Y. Hillervik C. Factors related to early termination of breastfeeding. Acta Paediatr Scand 1977; 66: 505-11.

19 Ekwo EF, Dusdieker L, Booth B. Psychological factors influencing the duration of breastfeeding by primigravidas. Acta Paediatr Scand 1984; 73: 241-7.

20 Salariya EM, Easton PM, Cater JI. Duration of breastfeeding after early initiation and frequent feeding. breastfeeding after early
Lancet 1978; ii: $1141-3$.

21 McCann MF, Liskin LS, Piotrow PT, Rinehart W, Fox C Breastfeeding, fertility and family planning. Population Reports Series f 1981; 24: 525-75.

22 Whichelow MJ, King BE. Breastfeeding and smoking. Arch Dis Child 1979; 54: 240-1.

23 Lyon AJ. The effects of smoking on breastfeeding. Arch Dis Child 1983: 58: 378-80.

24 Van Steenbergen WM, Kusin JA, De With C, Lacko E Jansen AAJ. Lactation performance of mothers with contrasting nutritional status in rural Kenya. Acta Paediat Scand 1983; 72: 805-10.

25 Butte NF, Garza C, Stuff E, O'Brian-Smith E, Nichols BL Effect of maternal diet and body composition on lactational performance. Am f Clin Nutr 1984; 39: 296-306.

26 Butte NF, Garza C. Anthropometry in the appraisal of lactation performance. In: Hamosh M, Goldman AS, eds. lactation performance. In: Hamosh M, Goldman AS, eds. Human lactation 2: Maternal and

27 Strode MA, Dewey KG, Lonnerdal B. Effects of short-term caloric restriction on lactational performance of wellcaloric restriction on lactational performance of well-
nourished women. Acta Paediatr Scand 1986; 75: 222-9.

28 Prentice AM, Paul AA, Prentice A, Black AE, Cole TJ Cross-cultural differences in lactational performance. In: Hamosh M, Goldman AS, eds. Human lactation 2; Maternal and environmental factors. New York: Plenum, 1986: 13-44.

29 Prentice AM, Prentice A. Energy costs of lactation. Annu Rev Nutr 1988; 8: 63-79.

30 Whichelow MJ. Caloric requirements for successful breastfeeding. Arch Dis Child 1975; 50: 669.

31 Whichelow MJ. Success and faliure of breastfeeding in relation to energy intake (abstract). Proc Nutr Soc 1976; 35: $62 \mathrm{~A}$

32 Whichelow MJ. Breastfeeding in Cambridge, England: factors affecting the mothers milk suppy. $\mathcal{F}$ Adv Nursing 1979; 4: 253-61.

33 Whichelow MJ, King BE, Taylor S. Maternal eating habits and the maintenance of breastfeeding (abstract) Proc Nutr Soc 1979; 38: 20A.

34 McKay H. A longitudinal study of breastfeeding in Geelong. Geelong, Australia; Deakin University, 1981. BSc Hons Thesis.

35 National Heart Foundation of Australia. Risk factor prevalence study 1980. Report No 1. Canberra: National Heart Foundation of Australia, 1983: 37.

36 Weiner JS, Lourine JA, eds. Human biology. A guide to field methods. IBP handbook No 9. Philadelpia FA Davis, 1969:

37 Daniel AE. Power, privilege and prestige: occupations in Australia. Australian Studies Series. Melbourne: Longman Cheshire, 1983. 
38 Australian Bureau of Statistics. Australian standard classification of occupations. Statistical classification. 1st ed. Canberra: ABS, 1986

39 Minitab Inc. Minitab Reference Manual Release 6. State College: Minitab Inc, 1988.

40 Dixon W, ed. BMDP statistical software manual. Berkeley: University of California Press, 1990.

41 Cox DR. Regression models and life-tables (with discussion). $f R$ Stat Soc 1972; B34: 187-220.

42 Kalbfleisch JD, Prentice RL. The statistical analysis of failure-time data. New York: John Wiley, 1980.

43 Australian Bureau of Statistics. Births Victoria 1984 Melbourne: ABS, 1985.

44 Health Commision of Victoria. Community Health Services. In: Seventh annual report 1984/85. Melbourne: Government Printer, 1985: 114.

45 National Heart Foundation of Australia. Risk factor prevalence study 1983. Report No 2. Canberra: National Heart Foundation of Australia, 1985: 35.

46 Hamill PVV, Drizd TA, Johnson CL, Reed RB, Roche AF Moore WM. Physical growth: National Centre for Health Statistics percentiles. Am f Clin Nutr 1979; 32: 607-29.

47 Gray-Donald K, Kramer MS, Munday S, Leduc DG. Effect of formula supplementation in the hospital of the duration of breast-feeding: a controlled clinical trial. Pediatrics 1985; 75; 514-8.
48 Kurinij N, Axelson ML, Forman MR, Weingold AB. Predicting duration of breastfeeding in a group of urban primiparae. Ecol Food Nutr 1984; 15: 281-91

49 Tamminen T, Verronen P, Saarikoski S, Goransson A, Tuomiranta $\mathrm{H}$. The influence of perinatal factors on breast feeding. Acta Paediatr Scand 1983; 72: 9-12.

50 Martin J, White A, eds. Infant feeding 1985. Social Survey Division, Office of Population Censuses and Surveys (OPCS). London: HMSO, 1988

51 Starling J, Fergusson DM, Horwood LJ, Taylor B. Breastfeeding success and failure. Aust Paediatr $\mathcal{f}$ 1979; 15: 271-4.

52 Weile B, Rubin DH, Krasilnikoff PA, Kuo HS, Jekel JF. Infant feeding patterns during the first year of life in Denmark: factors associated with the discontinuation of breastfeeding. $\mathcal{F}$ Clin Epidemiol 1990; 43: 1305-11.

53 de Chateau P, Holmberg H, Jakobssen K, Winberg J. A study of factors promoting and inhibiting lactation. Devel Med Child Neurol 1977; 19: 575-84.

54 Roberts SB, Cole TJ, Coward WA. Lactational performance in relation to energy intake in the baboon. Am f Clin Nutr 1985; 41 : $1270-6$.

55 Dugdale AE, Eaton-Evans J. The effect of lactation and other factors on post-partum changes in body-weight and triceps skinfold thickness. Br ₹ Nutr 1989; 61: 149-53. 